$\mathbb{T}$ periodica polytechnica

\author{
Civil Engineering \\ 58/3 (2014) 267 278 \\ doi: 10.3311/PPci.7531 \\ http://periodicapolytechnica.org/ci \\ Creative Commons Attribution (1) \\ RESEARCH ARTICLE
}

\section{Finite element and analytical computation of flash temperature}

\author{
László Sábitz / Ferenc Kolonits
}

Received 2014-05-24, revised 2014-06-16, accepted 2014-06-30

\begin{abstract}
When sliding occurs due to over-braking of a vehicle, intense heat is generated at the rail-wheel interface due the rollingsliding motion. Sliding means a moving frictional heat source. The resulting "flash" temperature greatly influences the course of proceedings on the contact patch. A thorough analysis of the wheel/rail contact requires a FEM-based model which is able to follow the thermo-mechanical processes in close neighborhood of the contact area. In order to validate whether the mesh in the FE model is sufficiently refined, analytical solutions were set up. After having performed the initial thermal finite element analysis, an analytical solution was developed for the same load case. The FE mesh was refined based on a comparison of the FE and analytical results. The effects of FE mesh size on the computational results were investigated. In certain cases, the analytical formulae derived were found to be more effective than FEM.
\end{abstract}

\section{Keywords}

railway braking $\cdot$ wheel/rail contact $\cdot$ macroscopic sliding . flash temperature $\cdot$ half-space $\cdot$ FEM validation

\section{László Sábitz}

Department of Aeronautics, Naval Architecture and Railway Vehicles, Budapest University of Technology and Economics, Múegyetem rkp. 3, H-1111 Budapest, Hungary

e-mail: 1sabitz@vrht.bme.hu

\section{Ferenc Kolonits}

Department of Aeronautics, Naval Architecture and Railway Vehicles, Budapest University of Technology and Economics, Múegyetem rkp. 3, H-1111 Budapest, Hungary

e-mail: fkolonits@vrht.bme.hu

\section{Introduction}

The proper rail/wheel contact conditions are of paramount importance for ensuring the safe operation of railways. The contact transfers the vertical load of the weight of the rolling stock. The load-bearing capacity of the mating parts of the contact strongly depends on characteristics such as Hertzian stress, creep, fatigue, friction etc. Instantaneous heat input and temperature rise also occurs - the flash. This appears in several applications and promoted the development of tribology. The first step was made by Blok [1] identifying the effect as a root cause of scuffing on gear wheels. The related questions have remained subjects of discussion and research ever since. Blok himself wrote about further development and generalization of the theory [2], and the effect of distribution of heat generated by friction was analyzed by Tanvir [3]. Abdel-Aal studied the temperature dependence of thermal conductivity [4]. Ertz and Knothe studied the analytical versus numerical approaches of temperature development [5]. There are analyses concerning high- and low-speed applications, Sutter and Ranc, based on measurements [6] and Kalin[7], respectively. Even recently, a quite new approach was proposed by Smith and Arnell focusing on contact of asperities [8]. An advanced wheel/rail contact model was presented by Tomberger et al. [9] in which the analytical solution of the flash temperature is implemented based on the method published by Ertz [10]. A further field of interest is the better grounding of experiments aimed to obtain tribologic parameters e.g. pin-ondisc [11]. A recent paper of $\mathrm{Li}$ et al. assessed thermal damage as the most important failure mode of wheel and rail [12]. Frictional heat arising from wheel sliding can cause martensite formation on the rail-head [13, 14], and also on the wheel [15]. The presence of hardened martensitic spots can lead to damage such as spalling on the rail surface [14] or the wheel surface [16]. The heat generation model had been further improved including plastic deformation work by Fischer et al. [17]. The thermal problem itself has to be integrated into the various geometries of the mating bodies and this is even more important if the subsequent damage e.g. thermal fatigue is analyzed. This may be realized by a suitable finite element model which is able to reflect the rapid thermal process, see Peng et al [18]. The ef- 
fects of heat convection and radiation on the flash temperature are neglibible in comparison with the effect of heat conduction, as was previously concluded by Lewis and Dwyer-Joyce [19].

In this paper, the effect of sudden short heat input, the temperature distribution and its change with time as the "heat pack" expands into the bulk of the bodies is analyzed. The geometry of the wheel profile contacting the rail is described in detail by an FE model. There, the transition from the starting "half-space" model to the real-dimension contacting bodies is followed. This "heat pack expansion" is an elementary constituent part of the real contact of moving surfaces. Different analytical methods have been tested in the past to solve the partial differential equation of heat conduction in solid bodies [20], but not all of them proved to be in good agreement with experimental results. The analytical solution of the heat transport problem is obtained by using the same method as in [21]. The heat conduction in the steel wheel is prominent in the radial direction [22].

The commercial finite element tool Patran was used to preand post-process the simulations [23], while solver Marc was applied for performing the numerical simulations [24]. There, the (varying) heat source marches on along the respective bodies, leaving a heat trace behind, like a torch or a comet. The full history could be reconstructed by a convolution-like procedure later. The significance of the results is that the necessary requirements (such as mesh density, model boundaries) are worked out for a finite element model capable of simulating the flash temperature and its diffusion into the rail or the wheel.

\section{Finite Element model construction}

The initial numerical model worked with here is shown in Fig. 1. A solid wheel with a highly worn profile was modelled. The wheel rim considered was radially thinned so that the row itself had a reduced thermal resistance compared to a new wheel rim. It was assumed that after applying a short-duration thermal load on the running surface, the ever evolving heat affected contact zone would reach the side boundaries of the wheel row geometry sooner in case of a radially thinned rim, than in case of a new, radially thicker rim. A thermal FE model applicable for the case of an extremely thinned wheel rim is predictably also usable for cases with new, or less worn wheels.

The mesh was made mostly of 8-node 'hexahedron' elements, with the element size increasing progressively with the distance from the wheel/rail contact region. The minimal edge length of $0.9 \mathrm{~mm}$ (perpendicularly to the tread surface) was applied in the proximity of the heat input area - the location where the largest temperature gradients were expected.

A steel railway wheel/rail contact was considered for the simulation with the following material constants:

Density: $\rho=7833 \mathrm{~kg} / \mathrm{m}^{3}$

Specific heat: $c=465 \mathrm{~J} / \mathrm{kgK}$

Heat conduction coefficient: $\lambda=54 \mathrm{~W} / \mathrm{mK}$

Heat diffusion coefficient: $\kappa=1.482 \cdot 10^{-5} \mathrm{~m}^{2} / \mathrm{s}$
The wheel/rail contact area was roughly approximated by a $6 \times 8 \mathrm{~mm}$ quad instead of the elliptical area to suit FEM: $(2 a) \times(2 b)=0.006 \times 0.008=48 \cdot 10^{-6} \mathrm{~m}^{2}$. The duration of the heat input was $T=0.06 \mathrm{~s}$. The thermal power applied and directed into the wheel rim was $1 \mathrm{~W}$, therefore, the energy density (directed orthogonally on the surface spanned by $x$ - $y$ axes, along the $z$-axis) was $q^{z}=208333 \mathrm{~W} / \mathrm{m}^{2}$. A cardinal question of FEM calculations is whether the mesh is as dense as necessary and sufficient. Refining the mesh beyond necessity is an useless computational effort, moreover, it may permit gross error and compromise even the reality. Therefore, a parallel analytical study was advisable in order to validate the FEM results. The thermal shock on a relatively small surface is a highly local phenomenon. While the heat input expands all around, after some time, a growing but limited volume of the wheel mass becomes affected. The process can be approximated by a thermal shock applied perpendicularly on a half space. The details of the actual wheel row geometry only come into the scope after some time, as the heat flow reaches these details (limiting surfaces etc.) and a tangible increase in temperature appears there.

\section{Numerical results and analytic approach}

\subsection{Thermal shock process modelled by FEM}

In the first set of simulations, a heat input was applied on the wheel which was considered to be uniformly distributed over the wheel/rail contact surface. This rectangular form contact area $(6 \times 8 \mathrm{~mm})$ was very small compared to the size of the wheel rim. A parameter study was performed in order to investigate the effect of heat convection to the environment. Thus, the simulation was repeated with two different heat convection coefficient values (of $5.6 \mathrm{~W} / \mathrm{m}^{2} \mathrm{~K}$ and $450 \mathrm{~W} / \mathrm{m}^{2} \mathrm{~K}$ ) and then a third simulation was carried out with the heat convection coefficient set to zero. After evaluating the temperature results of the three simulations, the temperature values of the three cases were practically the same, with a relative difference of less than $0.5 \%$. The heat loss by convection was therefore neglected in further simulations. The spatial- and temporal variation of wheel temperature is illustrated in a series of instantaneous temperature distribution snapshots (see Fig. 2- 6).

After the thermal shock, a quasi spherical temperature field evolves, as it is shown in Fig. 2-4. The maximum value of the instantaneous temperature decreases rapidly with the increasing radius of the sphere. In the early stage of the thermal process, the heat was conducted in a space which was assumed to be homogenous from the point of view of heat propagation. The phenomena can be treated as a half-space problem until the boundary surface of the wheel fully contains the thermal hemisphere. According to the numerical results, the shape of the solid body becomes important about 30 seconds after the end of the thermal shock, when the temperature field reaches the flange (see Fig. 5). From this moment on, a half-space heat conduction model would be no longer applicable for the wheel. However, the intensity of temperature by this time has already decreased 


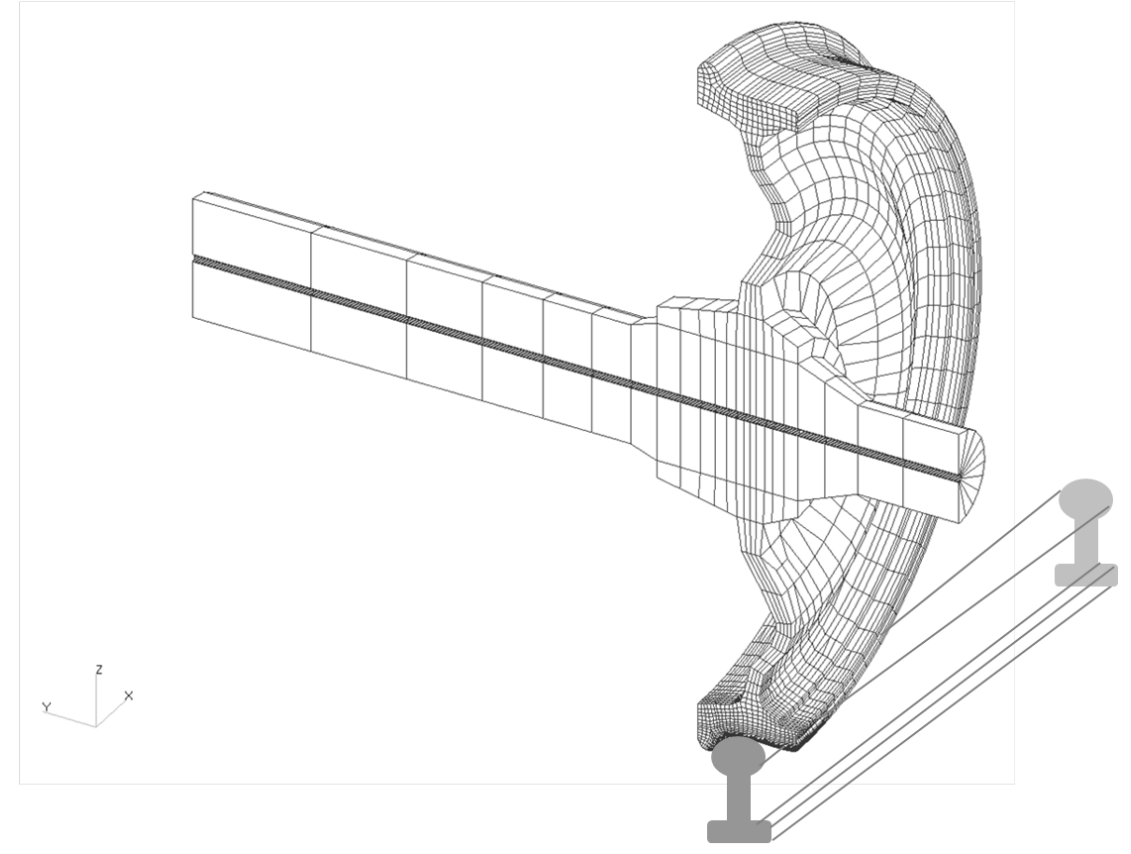

Fig. 1. Finite element model of a railway wheel-set
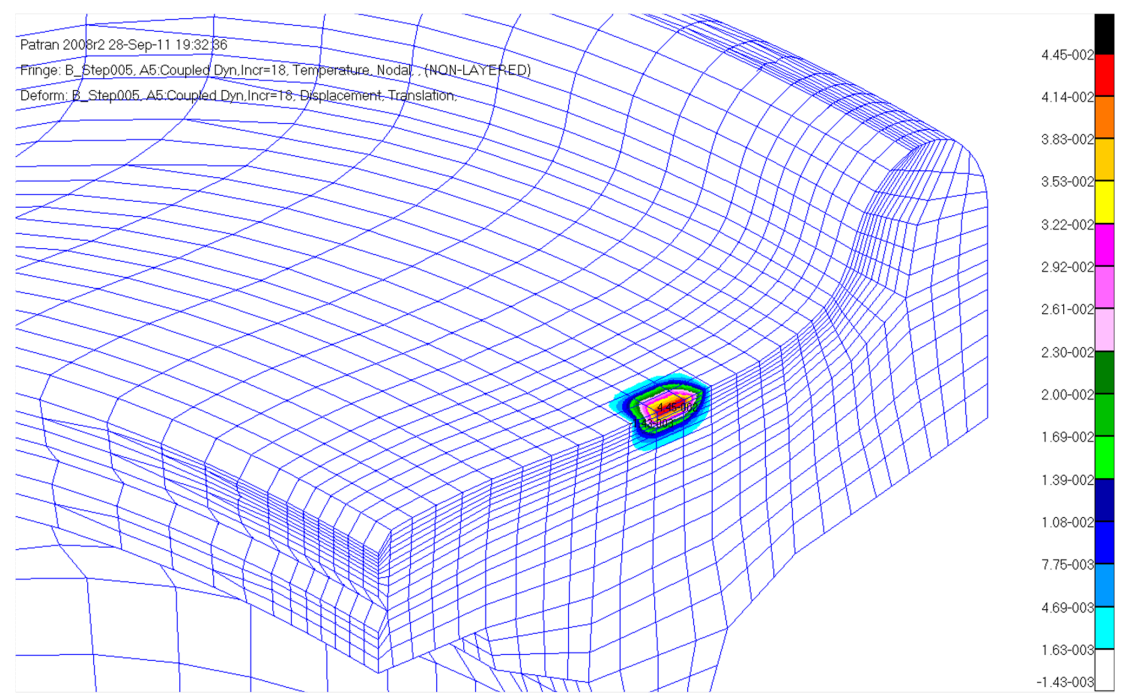

Fig. 2. Temperature distribution in the wheel $0.257 \mathrm{~s}$ after the end of heat input, the maximum surface temperature is $4.45 \cdot 10^{-2}{ }^{\circ} \mathrm{C}$ (initial temperature: $0{ }^{\circ} \mathrm{C}$ )
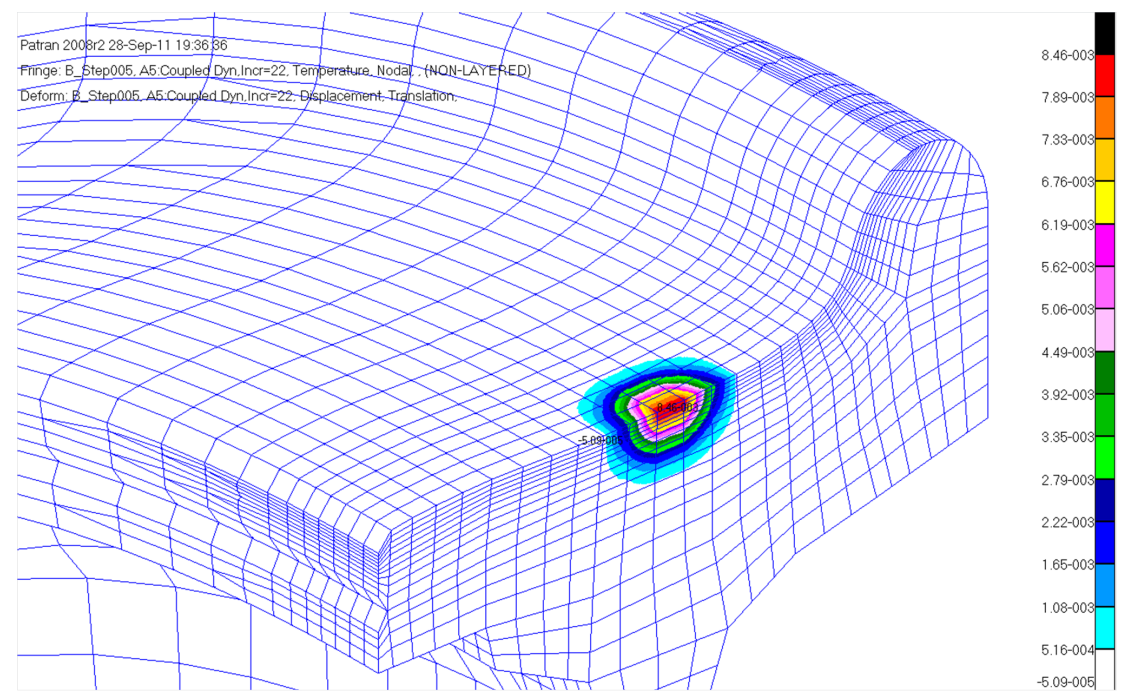

Fig. 3. Temperature distribution in the wheel $1.31 \mathrm{~s} \mathrm{after} \mathrm{heat} \mathrm{input,} \mathrm{the} \mathrm{maximum} \mathrm{surface} \mathrm{temperature} \mathrm{is} 8.46 \cdot 10^{-3}{ }^{\circ} \mathrm{C}$ (initial temperature: $0{ }^{\circ} \mathrm{C}$ ) 


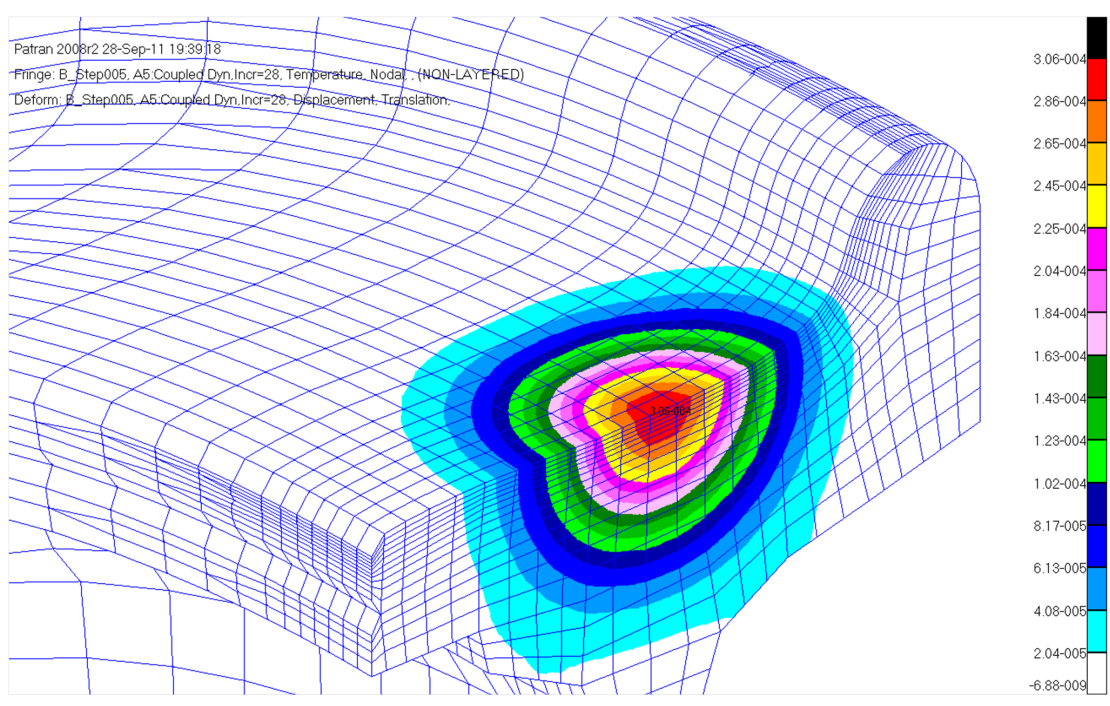

Fig. 4. Temperature distribution in the wheel $15 \mathrm{~s}$ after heat input, the maximum temperature is $3.06 \cdot 10^{-4}{ }^{\circ} \mathrm{C}$ (initial temperature: $0^{\circ} \mathrm{C}$ )
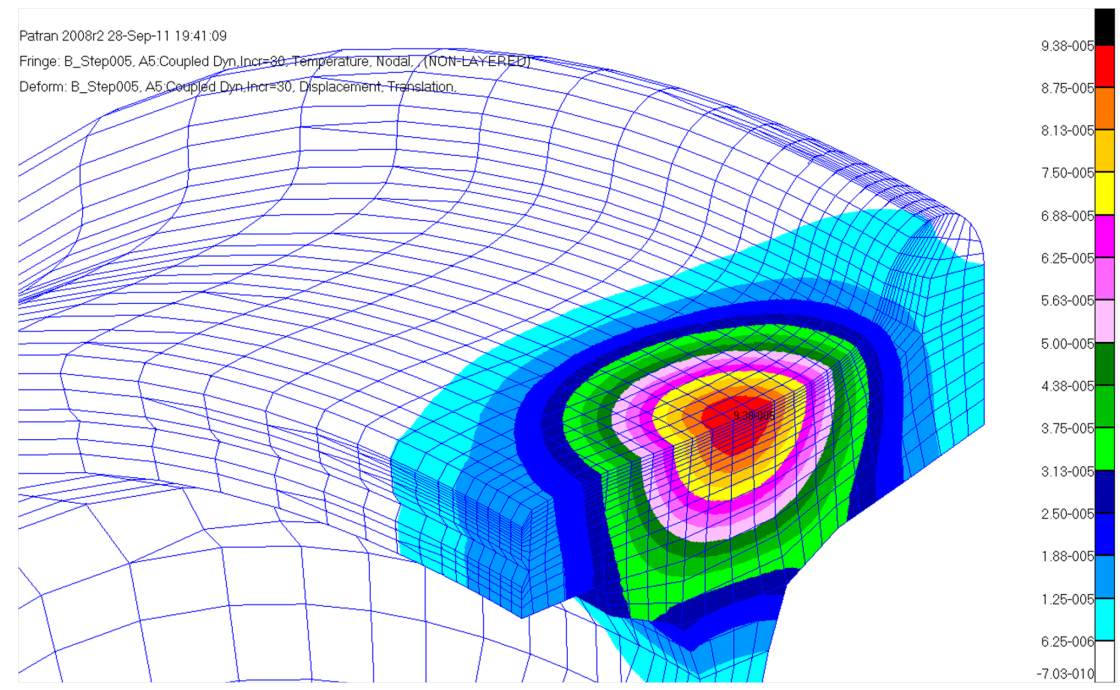

Fig. 5. Temperature distribution in the wheel $33.7 \mathrm{~s}$ after heat input, the maximum temperature is $9.38 \cdot 10^{-5}{ }^{\circ} \mathrm{C}$ (initial temperature: $0{ }^{\circ} \mathrm{C}$ )

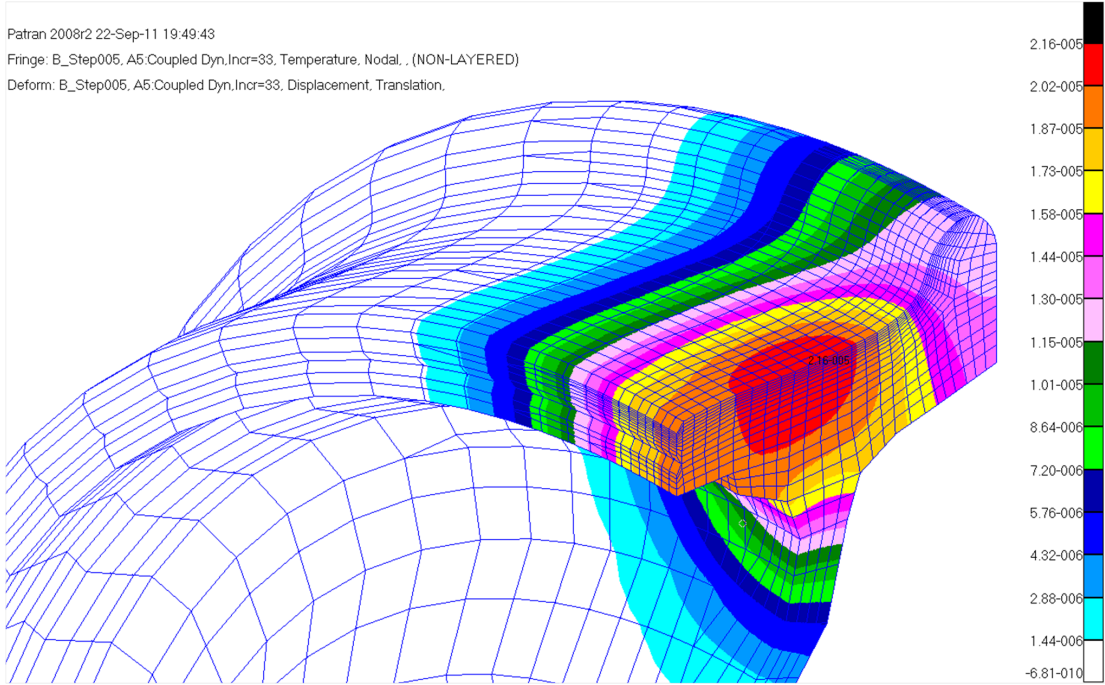

Fig. 6. Temperature distribution in the wheel $114 \mathrm{~s}$ after heat input, the maximum temperature is $2.16 \cdot 10^{-5}{ }^{\circ} \mathrm{C}$ (initial temperature: $0{ }^{\circ} \mathrm{C}$ ) 
to approximately zero (the maximal temperatures in Fig. 5 and Fig. 6 are in the order of $10^{-5}{ }^{\circ} \mathrm{C}$ ).

\subsection{Temperature distribution after a shock into a half space}

In order to obtain an overall picture of the temperature propagation procedure, let us apply a formula quoted by Carslaw and Jaeger [21] describing the history initiated by injecting a $q^{z}$ power density through a circular surface spot of radius $a$ into a half-space, during time $T$. For a continuous input in interval $[0, t]$, the growth of temperature under the center of the spot at depth $z$ is

$$
\vartheta(z, t)=\frac{2 q^{z} \sqrt{\kappa t}}{\lambda}\left[\operatorname{ierfc}\left(\frac{z}{2 \sqrt{\kappa t}}\right)-\operatorname{ierfc}\left(\frac{\sqrt{z^{2}+a^{2}}}{2 \sqrt{\kappa t}}\right)\right] .
$$

In Eq. (1), ierfc is the integral of the complementary error function [21]. If the input is terminated at time $T$, the temperature growth which should have been produced by continuing the heating after that limit shall be subtracted,

$$
\vartheta(z, t)_{t \geq T}=\vartheta(z, t-T)-\vartheta(z, t)
$$

As a characteristic/reference value for the over-all temperature distribution, the temperature in the surface center and at time $T$ (as heating has just been finished) can be considered. Eq. (1) comes from Eq. (5), page 264 of ref. [21], with some nomenclature change. If $z=0$, the ierfc can be determined in closed formula, the result will be

$$
\begin{aligned}
\Theta_{T}= & \frac{2 q^{z} \sqrt{\kappa T}}{\lambda}\left\{\frac{1}{\sqrt{\pi}} \cdot\left[1-\exp \left(-\frac{a^{2}}{4 \kappa T}\right)\right]+\right. \\
& \left.+\frac{a}{2 \sqrt{\kappa T}} \operatorname{erfc}\left(\frac{a}{2 \sqrt{\kappa T}}\right)\right\} .
\end{aligned}
$$

If the $6 \times 8 \mathrm{~mm}$ heated spot is to be substituted by an equivalent circular one, then $a=0.0039088 \mathrm{~m}$. The reference temperature according to (3) will be $\Theta_{T}=0.4101 \mathrm{~K} /(1 \mathrm{~W})$. The heatingup yields steadily growing temperatures, computable by Eqs. (1) and (3). More attention has to be given to the aftermath, the response of the half-space to the thermal excitation. Fig. 7 shows the temperature development with time from $T+0.5 \mu \mathrm{s} \ldots 0.5 \mathrm{~s}$ and along distance $0.5 \mu \mathrm{m}$. . .5 mm. The projection onto the basis plane $x-y$ shows that the "heat pack" fed into the half-space gets dispersed rather fast. The details around the start can be visualized better using a log scale (Fig. 8). The results are related to heat flow input of 1 Watt, later the reference will be omitted.

\subsection{Relation of FEM to analytical results}

Temperatures at the center of the heated spot computed by FEM and by analytical formulae are shown in Fig. 9, and for a longer time with log scale in Fig. 10

The curves up to $0.6 \mathrm{~s}$ are similar but the approximation is very poor. Thereafter, the values lay nearer to each other. However, this is the range where the temperatures have already fallen below a tenth of the reference temperature. Fig. 10 embraces a longer, time-span of about a day on a logarithmic scale. It shows either that these minuscule values are equal or that both are becoming submerged in numerical noise. Some additional information might be drawn, however, if the temperature scale is also logarithmic (Fig. 11).

According to the curves in Fig. 11, they are of similar character roughly up to $\log t=1.6, t=39.8 \mathrm{~s}$, where they diverge. The "similar" means here a relative difference of $\pm 30 \%$ which could surely be reduced by a refined mesh. The apparent turning point, however, has to be interpreted otherwise. At locations sufficiently distant from the hot spot, the evolution of temperatures does not depend on the distribution details of the heat input. The distance is sufficient if the size of the hot spot is negligible related to it - a thermal interpretation of Saint-Venant's principle, well-known from mechanics. The relation of the central temperatures to those at distance $x$ is about $\exp \left(-x^{2} /(4 \kappa t)\right)$. With that, one might compute at what a distance a non-negligible, say $10 \%$, temperature growth appears in $39.8 \mathrm{~s}$. The result is $0.0737 \mathrm{~m}$. The thickness of the wheel rim around the hot spot is around $60-70 \mathrm{~mm}$. This means that the heat flow reaches the boundaries of the object and the process should not be modeled further by an unlimited half-space. The analytical formula under-estimates the heat dissipated, while the FEM rightly indicates higher temperatures.

\subsection{Refining the mesh at the heat input}

In order to bring the results of the two approaches nearer to each other, let the details of heat input be investigated. The FEM does not compute the central temperature of the hot spot exactly. The result is a kind of average over the affected elements. Following this, the analytical approximation of the temperature distribution of the hot spot is evaluated and is shown in Fig. 12.

$$
\vartheta(\xi, t)=\frac{a q^{z}}{\lambda} \int_{0}^{\infty} J_{0}(u \xi) J_{1}(u) \operatorname{erf}\left(u \frac{\sqrt{\kappa t}}{a}\right) \frac{d u}{u} .
$$

In Eq. (4), $J_{0}$ and $J_{1}$ stand for the Bessel functions of first kind $\left(0\right.$ order and $1^{s t}$ order [21]). At $T=0.06 \mathrm{~s}$, the FEM gives $0.2962 \mathrm{~K}$. The analytic maximum is $0.4101 \mathrm{~K}$. The integral average over the hot spot is $0.3484 \mathrm{~K}$. The simple arithmetic average with central value and border ones is $0.2971 \mathrm{~K}$.

Taking a refined picture into consideration, the gap between the results given by the two methods will be closed. In order to show this effect "in vivo", a refined FEM model has been set up. This refers only to a half-space, beyond that the present analytic approach becomes invalid. The refined FE model contained $0.16 \times 0.16 \times 0.16 \mathrm{~mm}$ cubic elements in the heat input area. This means that the contact patch length was 37.5 times of the element size, while the contact width was 50 times of the element edge length. The higher mesh density provided more accurate results than the model introduced in Fig. 1. Taking advantage of the symmetry of the contact area, only one quarter of the 'halfspace' was represented, with the element size increasing with 


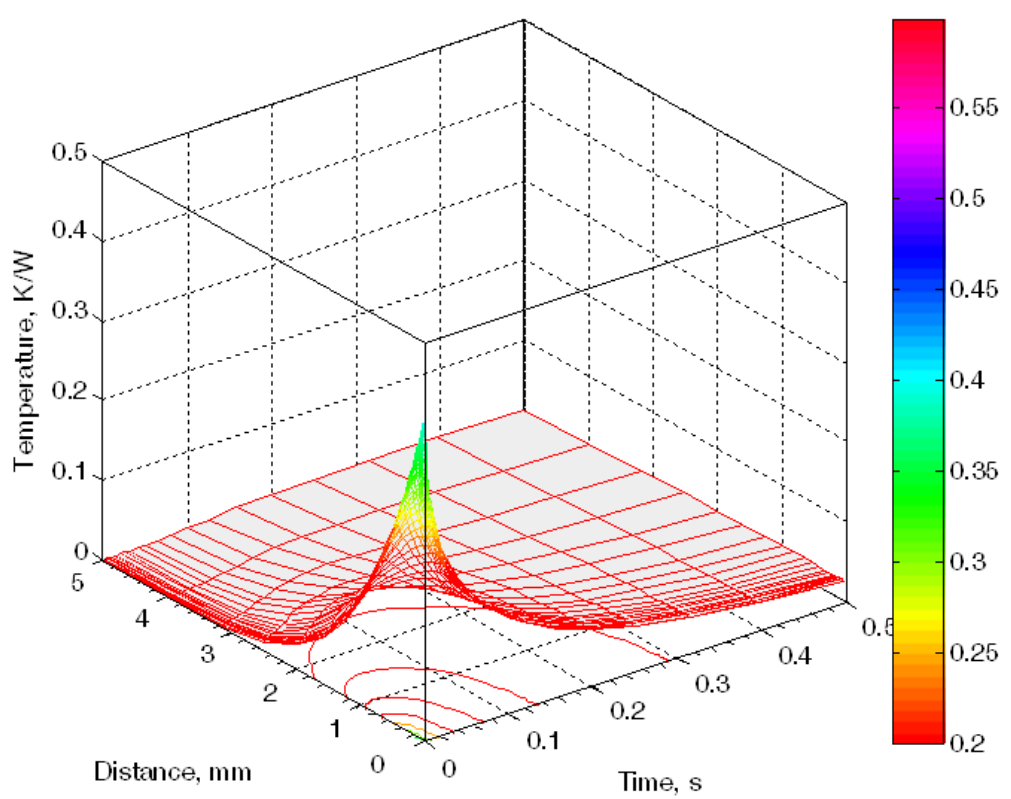

Fig. 7. Temperature distribution in space/time, respectively

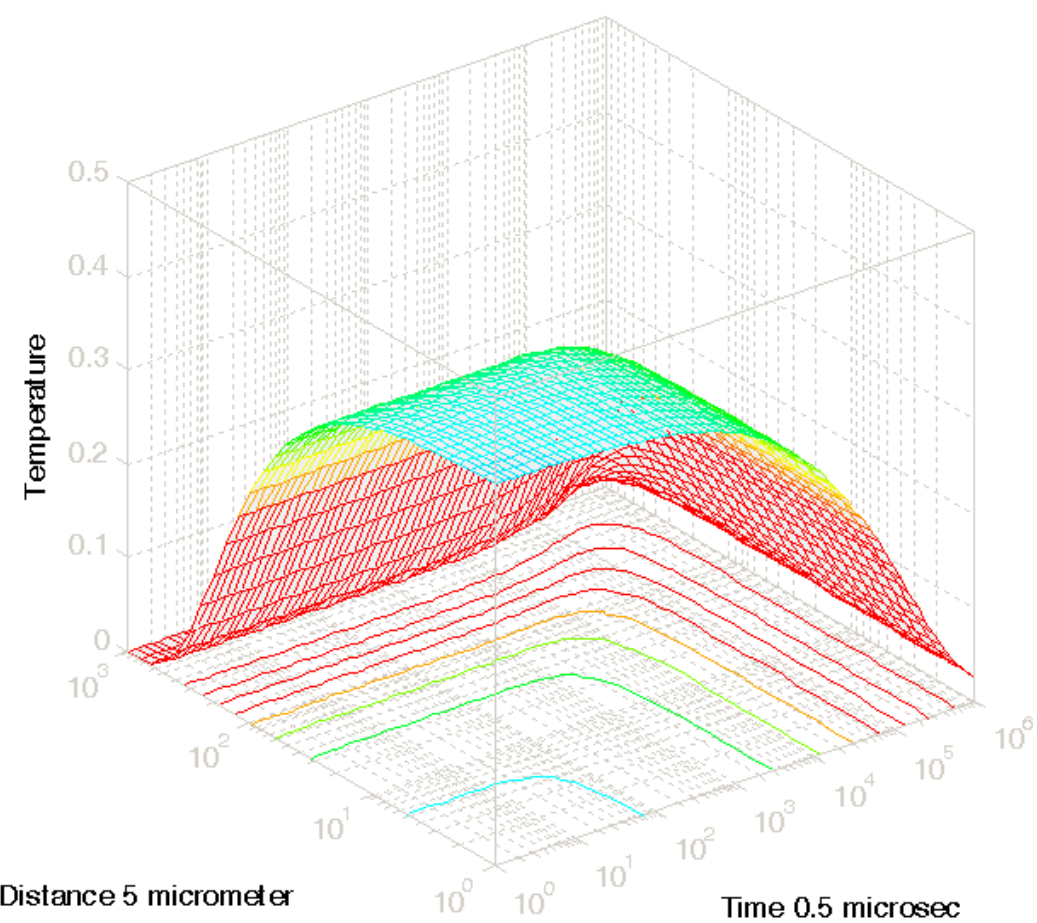

Fig. 8. Temperature distribution as of Fig. 7 on log-log scale 


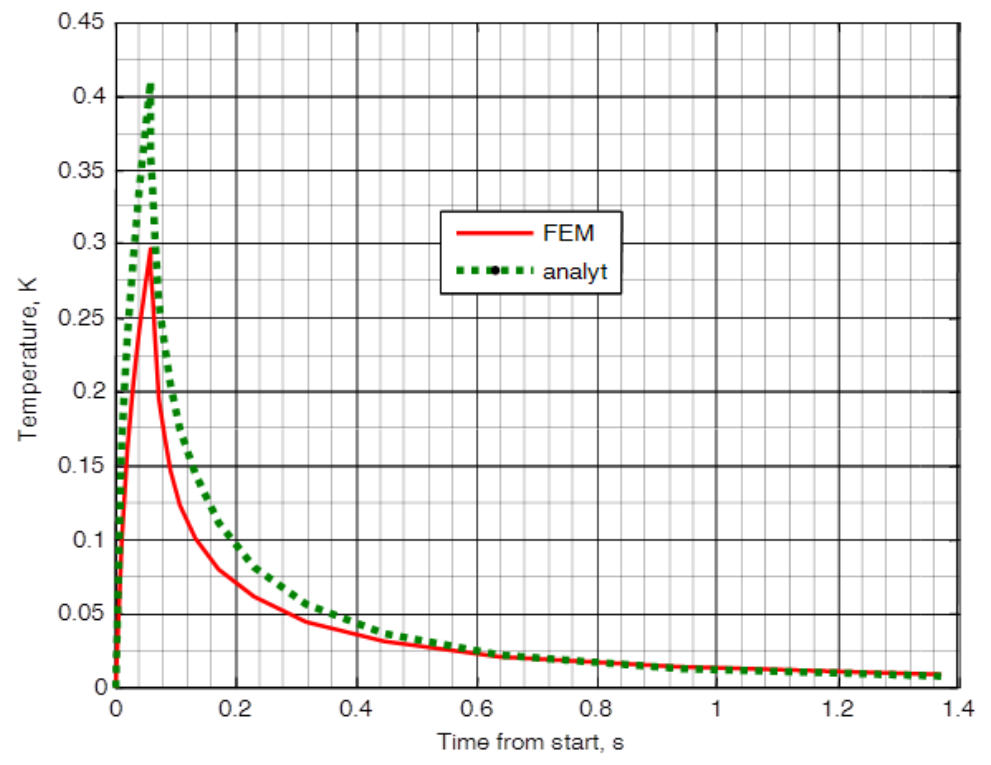

Fig. 9. Time variation of temperature, FEM vs. analytic results

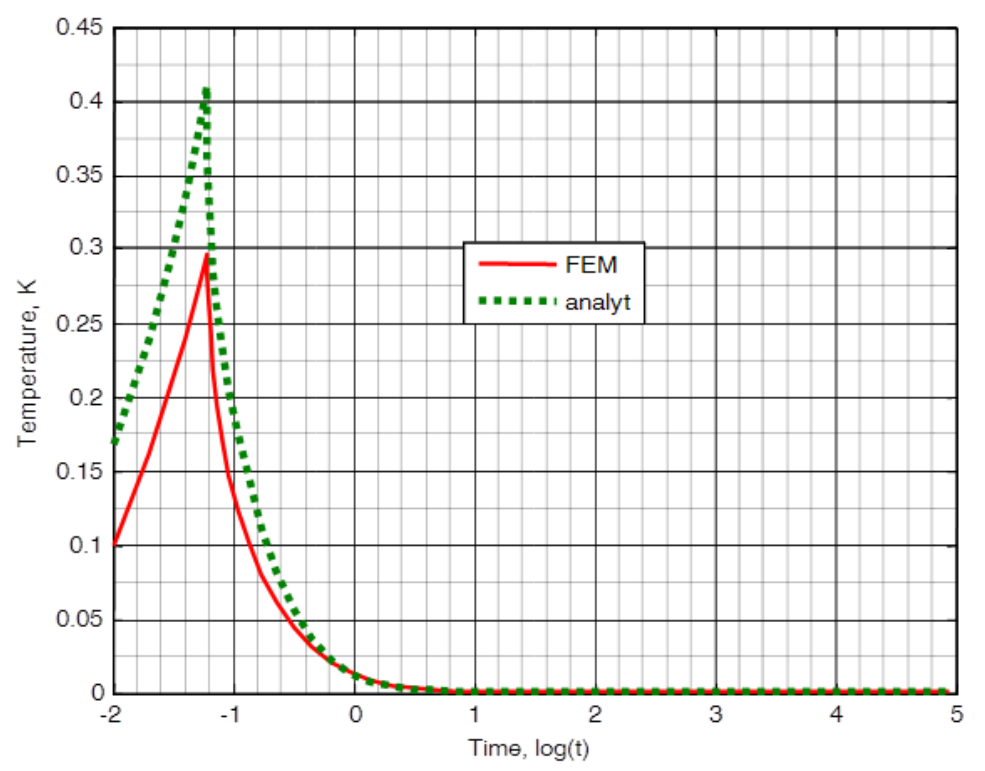

Fig. 10. Temperatures shown on a logarithmic time scale 


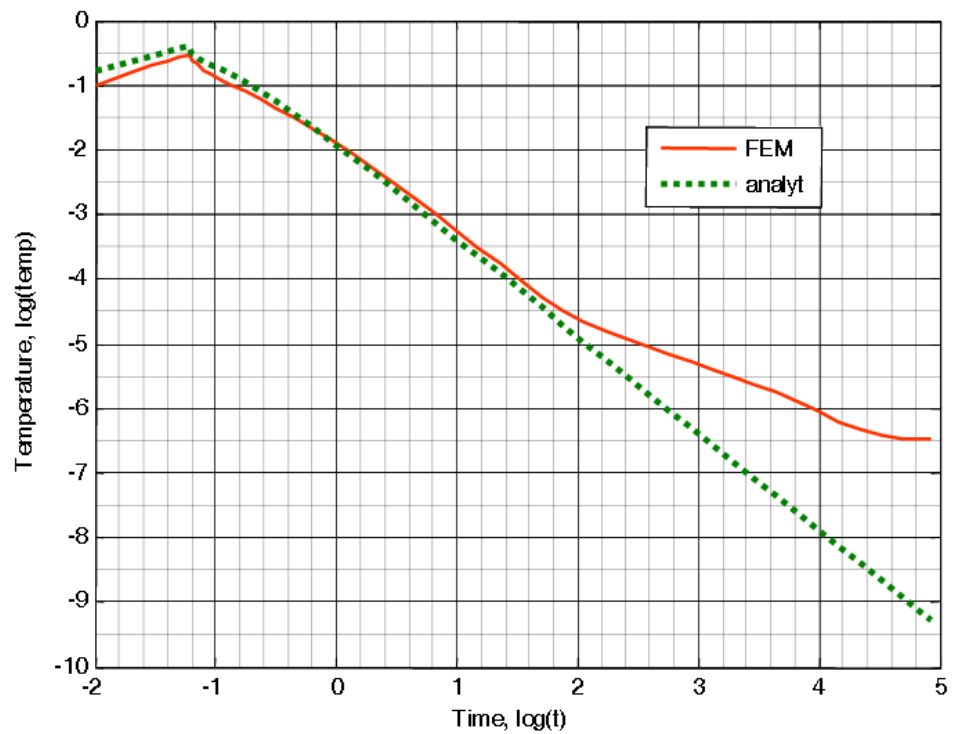

Fig. 11. Temperature vs. time using log-log scale

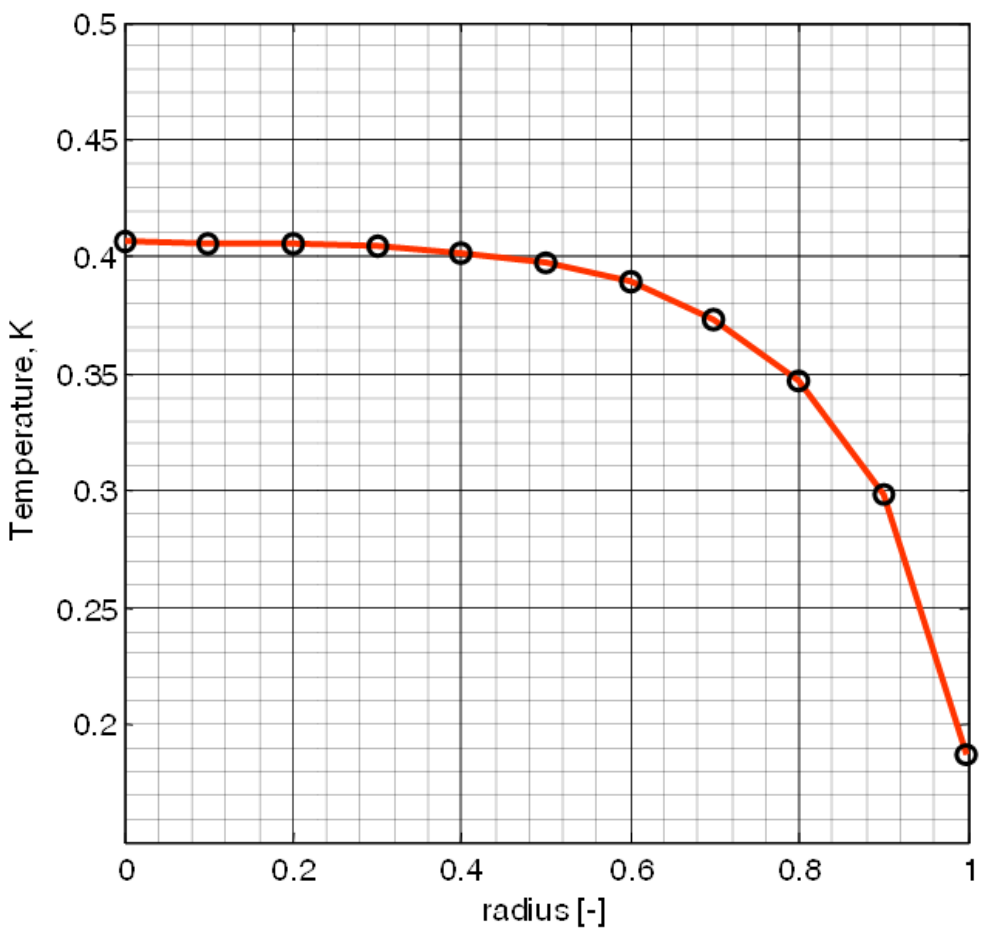

Fig. 12. Temperature distribution of the hot spot at time $T$ 
distance from the heat input. The temperature fields of the new model, at time $t=0.06 \mathrm{~s}$ and $t=0.172 \mathrm{~s}$ are shown in Figs. 13 and 14 , respectively.

After $t=0.172 \mathrm{~s}$, in Fig. 14, one may see that the field affected by the thermal shock reaches a region where the finite elements are distorted. Until this point, the temperature of the center of the heat input area determined by the FE solver shows a good agreement with the analytical solution. Comparing the results in Fig. 15, one can see that they fit satisfactorily to $0.16 \mathrm{~s}$. After that, FEM yields a slightly higher value, probably because the heat flow partially leaves the fine meshed volume, but this section is quite irrelevant from the point of view of the present investigation.

\subsection{General remarks on mesh sensitivity}

The previous procedures, calculations and results realize an approach to a more general problem of FEM calculations, i.e. how to build the mesh for them. An analytic method, although it may be theoretically exact, cannot follow complicated geometries and varying (e.g. material) parameters. The FE mesh must be dense enough, but not too much, to have enough resolution for these local variations, and at the same time avoid unnecessary detail. The critical limits are the size of the system matrix (due to time and storage consumption) and its conditioning or definiteness (its tendency to heap up numerical errors - measured by ratio of its extreme eigenvalues). FEs of uniform size, although simple, may give an oversized matrix, the conditioning of which gets worse with its size. It is more prudent to fit the mesh size to the guessed gradient of variations of the field under study, applying larger elements where variations are fading away. These elements disturb the norm relations of matrix rows/columns and its conditioning. At the same time, however, the over-all size will diminish with healthy consequences. These two effects are contrary and only a multi-pass procedure may allow iterative development as above. There are several proposals to develop a task-oriented mesh automatically, with error estimation, but without qualified success.

\section{Conclusions}

FEM results can be validated by analytical formulae considering a heat shock and the resulting temperature distribution in a half-space. Whether this approach satisfactorily covers the process evolution depends on the size of the object. In the case investigated here, if the heat flow had exceeded the boundaries of the model, the temperature would have fallen to a technically negligible level. It must be kept in mind that all computations refer to a stationary heat source.

If an approximation of the effect of a moving heat source is required, a numerically performed convolution process has to be continued with the introduced elementary steps, where the integrating algorithm must be prudently chosen.

A remark concerning further applications has to be made. Under the present conditions, the velocity of the heat source is $v=2 b / T=0.008 / 0.06=0.133 \mathrm{~m} / \mathrm{s}$. This is apt for the condition of an over - braked wheel which is sliding but still rotating. According to Blok's fundamental results, the principal setup of temperature flow depends on the relation of the convective and conductive heat flow (Pèclet-number), $P e=v b / \kappa$. If this is greater than 20 (or a lower value by other authors), the principal direction of heat flow is inwards into the mass, and the components parallel to the surface may be neglected. Now, $P e=0.133[\mathrm{~m} / \mathrm{s}] \times 0.004[\mathrm{~m}] / 1.482 .10^{-5}\left[\mathrm{~m}^{2} / \mathrm{s}\right]=35.9$ and the velocity of the heat source is extremely low. This fact deserves attention.

The heat distribution in railway wheels and rails generated by the sliding contact of the wheel on rail is a highly localized effect. The required finite element size and model boundaries were worked out for the wheel/rail contact case discussed. Since the Pèclet-number is typically higher than 20, an analytical solution of the 1-dimensional heat conduction process into a half space is an effective method for computing the flash temperature. Simulation of the peak temperature by FEM gave correct results only after significant refinement of the mesh, with an element size being 50 times smaller than the contact patch width. The refined model was extended to a size equal to approximately 6 times the size of the contact area in all directions. The FE and analytical results showed good correlation when the simulation used mostly uniform cubic elements. When distorted quad elements were used, the accuracy of the solution started to decrease, but the sudden temperature decrease made the error insignificant.

The highly localized nature of the heating up initiates secondary effects worth of consideration. The thermal gradients around would be also high, which indicate high thermal stresses. There will appear also a high local thermal expansion zone embedded in a low temperature environment. The wart-like modification of surface leads to changes in contact geometry. The studies presented here may render an initial point for pursue these topics. 


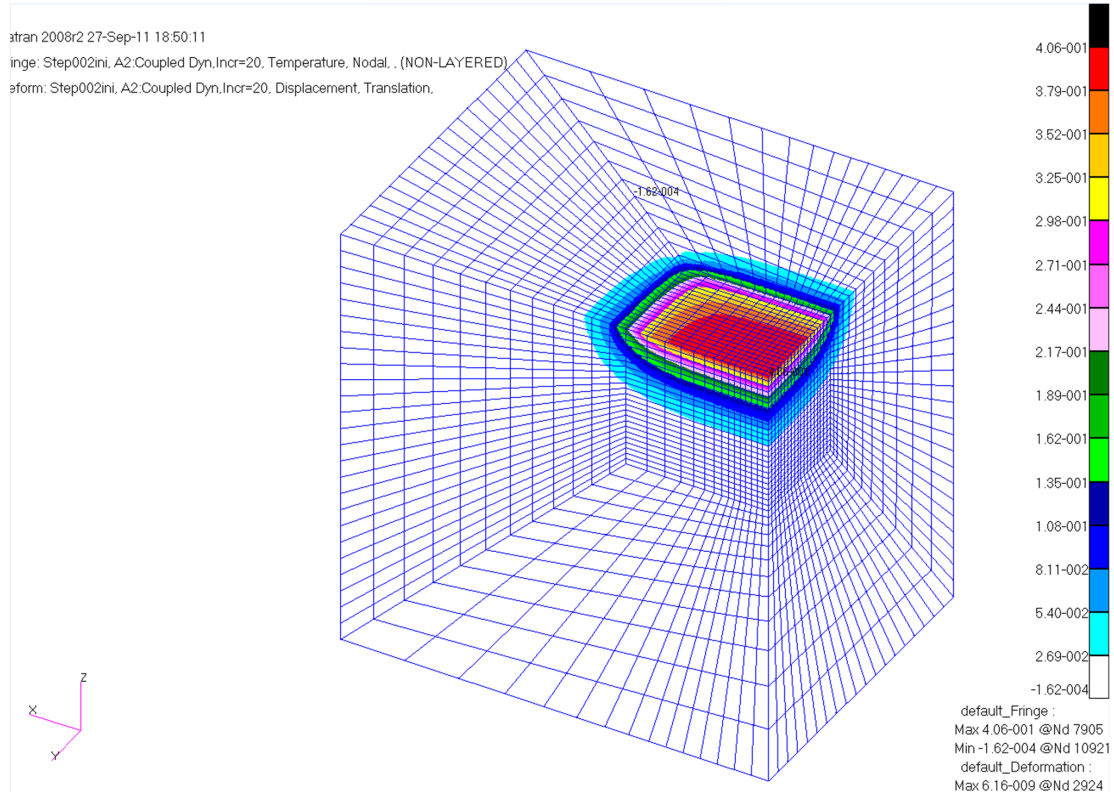

Fig. 13. Temperature distribution in the refined $\mathrm{FE}$ model at $\mathrm{t}=0.06 \mathrm{~s}$ (end of heat input), the maximum temperature is: $4.06 \cdot 10^{-1}{ }^{\circ} \mathrm{C}$

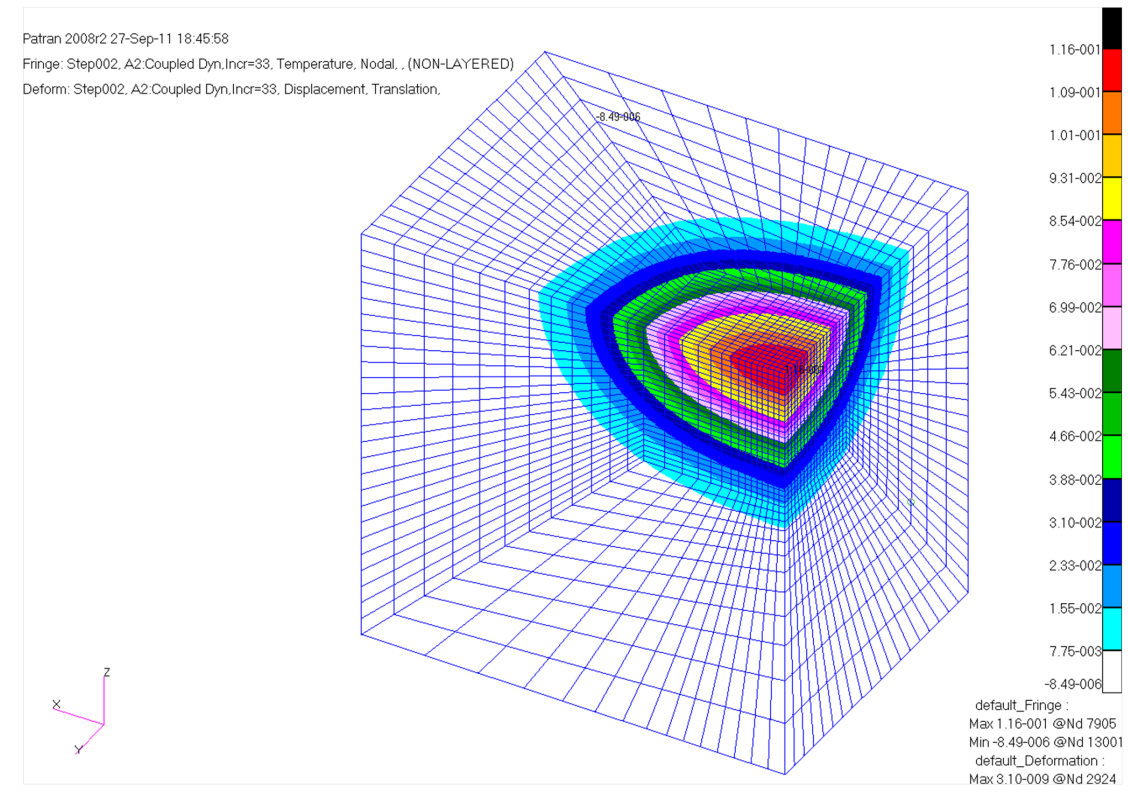

Fig. 14. Temperature distribution in the refined FE model at $\mathrm{t}=0.172 \mathrm{~s}$, the maximum temperature is: $1.16 \cdot 10^{-1}{ }^{\circ} \mathrm{C}$. 


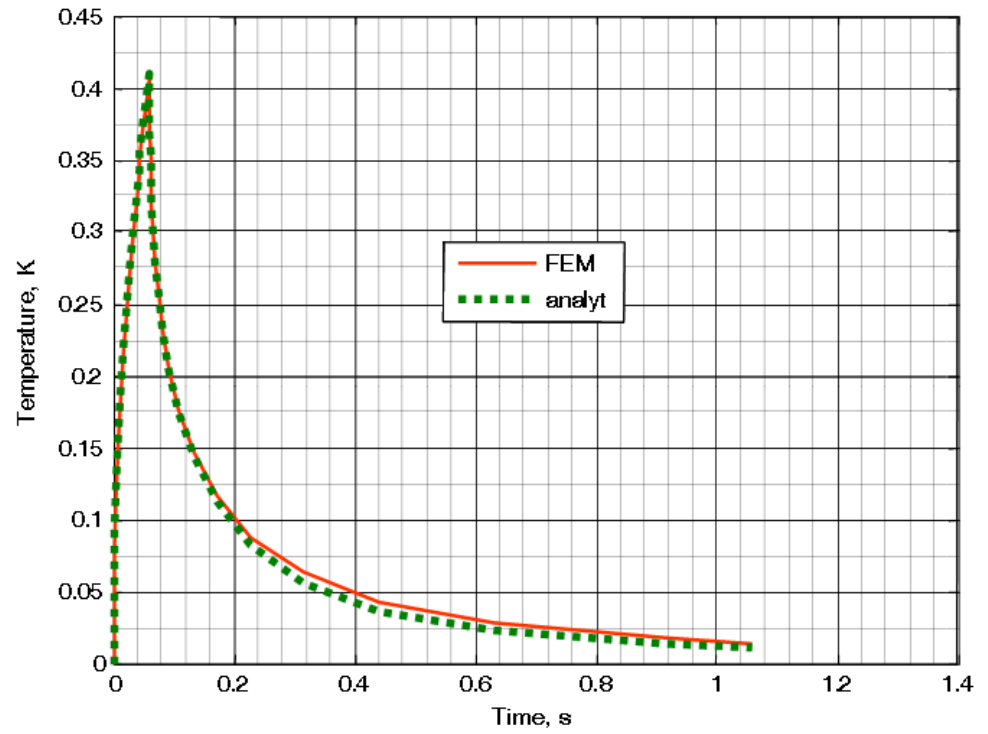

Fig. 15. A refined FEM model vs. analytic results 


\section{References}

1 Blok $\mathbf{H}$, Theoretical study of temperature rise at surfaces of actual contacts under oiliness lubricating conditions, In: Proc. Gen. Discuss. Lubricat., Inst. Mech. Eng.; London, UK, 1937, pp. 222-235.

2 Blok H, The flash temperature concept, Wear, 6, (1963), 483-494, DOI 10.1016/0043-1648(63)90283-7

3 Tanvir MA, Temperature rise due to slip between wheel and rail - an analytical solution for Hertzian contact, Wear, 61, (1980), 295-308, DOI 10.1016/0043-1648(80)90293-8

4 Abdel-Aal HA, A remark on the flash temperature theory, International Communications in Heat and Mass Transfer, 24(2), (1997), 241-250.

5 Ertz M, Knothe K, A comparison of analytical and numerical methods for the calculation of temperatures in wheel/rail contact, Wear, 253, (2002), 498508.

6 Sutter G, Ranc N, Flash temperature measurement during dry friction process at high sliding speed, Wear, 268, (2010), 1237-1242, DOI 10.1016/j.wear.2010.01.019

7 Kalin M, Influence of flash temperatures on the tribological behaviour in lowspeed sliding: a review, Materials Science and Engineering A, 374, (2004), 390-397, DOI 10.1016/j.msea.2004.03.031

8 Smith EH, Arnell RD, A New Approach to the Calculation of Flash Temperatures in Dry, Sliding Contacts, Tribology Letters, 52(3), (2013), 407-414, DOI $10.1007 / \mathrm{s} 11249-013-0224-9$

9 Tomberger C, Dietmaier P, Sextro W, Six K, Friction in wheel-rail contact: A model comprising interfacial fluids, surface roughness and temperature, Wear, 271, (2011), 2-12, DOI 10.1016/j.wear.2010.10.025

10 Erzt M, Temperatur, Materialbeanspruchung und Kraftschluss im RadSchiene-Kontakt, Dissertation, TU Berlin, 2003.

11 Kolonits F, Simplified thermal model of a pin-on-disc experiment, In: Zobory I (ed.), Proceedings of the 13th Mini Conference on Vehicle System Dynamics, Identification and Anomalies; Budapest, Hungary, 2014.

12 Li W., Wen ZF, Jin XS, Wu L, Numerical analysis of rolling-sliding contact with the frictional heat in rail, Chinese Journal of Mechanical Engineering, 27, (2012), 41-49, DOI 10.3901/CJME.2014.01.041

13 Steenbergen MJMM, Rail Surface Layer Modification under Train Operation, Second International Conference on Railway Technology: Research, Development and Maintenance, In: Pombo J (ed.), Proceedings of the Second International Conference on Railway Technology: Research, Develop- ment and Maintenance, Civil-Comp Press; Stirlingshire, UK, 2014, p. Paper 107, DOI $10.4203 / \mathrm{ccp} .104 .107$

14 Sábitz L, Zobory I, On Simulating the Thermal Conditions of Martensite Formation on Railway Wheel Treads, Second International Conference on Railway Technology: Research, Development and Maintenance, In: Pombo $\mathbf{J}$ (ed.), Proceedings of the Second International Conference on Railway Technology: Research, Development and Maintenance, Civil-Comp Press; Stirlingshire, UK, 2014, p. Paper 105, DOI 10.4203/ccp.104.105

15 Goryacheva IG, Zakharov SM, Torskaya EV, Rolling Contact Fatigue and Wear of Wheel/Rail Simulation: Wheel Thermomechanical Defects in the Russian Railway, Second International Conference on Railway Technology: Research, Development and Maintenance, In: Pombo J (ed.), Proceedings of the Second International Conference on Railway Technology: Research, Development and Maintenance, Civil-Comp Press; Stirlingshire, UK, 2014, p. Paper 103, DOI 10.4203/ccp.104.103

16 Day D, Harder RF, Costello M, An overview of freight vehicle wheel spalling, 5th International Conference on Railway Bogies and Running Gears, In: Zobory I (ed.), Proceedings of the 5th International Conference on Railway Bogies and Running Gears, Department of Railway Vehicles, BUTE; Budapest, Hungary, 2001, pp. 229-238.

17 Fischer FD, Daves W, Werner EA, On the temperature in the wheel-rail rolling contact, Fatigue and Fracture of Engineering Materials and Structures, 26, (2003), 999-1006, DOI 10.1046/j.1460-2695.2003.00700.x

18 Peng D, Jones R, Constable T, A study into crack growth in a railway wheel under thermal stop brake loading spectrum, Engineering Failure Analysis, 25, (2012), 280-290, DOI 10.1016/j.engfailanal.2012.05.018

19 Lewis R, Dwyer-Joyce RS, Wear mechanisms and transitions in railway wheel steels, Proceedings of the Institution of Mechanical Engineers Part J: Journal of Engineering Tribology, 218, (2004), 467-478, DOI 10.1243/1350650042794815

20 Windarta, Bin Sudin M, Baharom MB, Prediction of Contact Temperature on Interaction between Rail and Wheel Materials Using Pin-onDisc Method, Journal of Applied Sciences, 12, (2012), 2424-2429, DOI 10.3923/jas.2012.2424.2429

21 Carslaw HS, Jaeger JC, Conduction of heat in solids, 2nd, Clarendon Press; Oxford, UK, 1959.

22 Gallardo-Hernandez EA, Lewis R, Dwyer-Joyce RS, Temperature in a twin-disc wheel/rail contact simulation, Tribology International, 39, (2006), 1653-1663, DOI $10.1016 / \mathrm{j}$.triboint.2006.01.028

23 PATRAN 2008 User's Guide, MSC Software Corporation, 2008.

24 MARC 2008 User's Guide, MSC Software Corporation, 2008. 